DOI: $10.20472 /$ IAC.2019.048.025

\author{
YOUNG-HAN KIM \\ Sungkyunkwan University, South Korea
}

HANJOON JUNG

Tianjin University, China

\title{
TIMING OF GOVERNMENT INTERVENTION AND THE MULTIPLE EQUILIBRIA OF CURRENCY CRISIS
}

\begin{abstract}
:
This paper examines how currency crisis is affected by different timing of government intervention in the currency market. Since the seminal paper of Morris and Shin (1998), which shows that the self-fulfilling crisis can be avoided when noisy signals are considered, the conditions for the multiple equilibria have been widely studied. We contribute the studies by focusing on the timing of government intervention in the currency market. When the government intervenes in the market as a first mover, while speculators move as a second mover, the unique equilibrium of the currency market collapses since speculators can successfully coordinate after observing the government's decisions. If the government moves as a second mover as in the case of Morris and Shin (1998), the unique equilibrium exists with noisy signals. When the government and speculators move simultaneously, there is no equilibrium with noisy information while there might be a unique equilibrium with perfect information. The results implicate that rash government intervention as a first mover might aggravate the currency crisis since the speculators have bigger opportunity for speculative coordination after observing the government's action. The equilibria are also defined when the government intervention occurs in a repeated fashion, and the implications are discussed.
\end{abstract}

\section{Keywords:}

Currency crises, government intervention timing, multiple equilibria, unique equilibrium in currency regime

JEL Classification: F42, E61, P11 